\title{
DIAGÊNESE DOS ARENITOS DO GRUPO ITARARÉ, PERMOCARBONÍFERO, BACIA DO PARANÁ
}

\author{
LUCIANE BERGAMIN BOCARDI' ${ }^{1}$, LUIZ ALBERTO FERNANDES ${ }^{2}$, \\ SIDNEI PIRES ROSTIROLLA ${ }^{3}$ \& CIRO JORGE APPI ${ }^{4}$
}

\begin{abstract}
Resumo Os arenitos do Grupo Itararé (Carbonífero-Permiano) são considerados reservatórios potenciais de hidrocarbonetos na Bacia do Paraná. São constituídos por quartzo, feldspatos e fragmentos líticos, podendo ser classificados como quartzoarenitos, sublitoarenitos e subarcóseos. Os principais processos diagenéticos que afetaram estes arenitos foram compactação, autigênse de quartzo, carbonatos, sulfatos, argilominerais e dissolução. Sua evolução diagenética compreende eodiagênese, mesodiagênese e telodiagênese. Durante o estágio eodiagenético destaca-se a cimentação carbonática e a compactação mecânica. Na mesodiagênese ocorre significativa compactação química, crescimentos sintaxiais de quartzo, cimentação por anidrita, dissolução parcial de cimentos e minerais instáveis, principalmente feldspatos, substituição de grãos por carbonatos e sulfatos assim como autigênese de argilominerais. O soterramento profundo, por longo tempo ou em condições de temperatura mais elevada característico do estágio mesodiagenético é indicado pelo índice de empacotamento fechado ( $\mathrm{Pp}>55$ ), além da presença de contatos côncavo-convexos e suturados. A telodiagênese é importante nas porções aflorantes do Grupo Itararé, onde a dissolução de minerais instáveis e cimentos foi muito intensa, seguida de preenchimento do espaço gerado por óxido de ferro. Os processos diagenéticos afetaram a qualidade dos reservatórios arenosos, principalmente quanto à redução da porosidade por compactação.
\end{abstract}

Palavras-chave: diagênese, arenitos, Grupo Itararé, reservatórios.

\begin{abstract}
DIAGENESIS IN THE CARBONIFEROUS-PERMIAN SANDSTONES OF THE ITARARÉ GROUP, PARANA BASIN, BRAZIL. Carboniferous-Permian sandstones of the Itararé Group are potential reservoirs for hydrocarbons in the Paraná Basin. Sandstones are constituted by quartz, feldspar and rock fragments and can be classified as quartzarenites, sublitharenites and subarkoses. The sandstones of the Itararé Group were affected by diagenetic processes like compaction, quartz authigenesis, cementation by carbonates, sulfates, clay minerals and dissolution. The diagenetic evolution of the Itararé Group sandstones comprises eodiagenesis, mesodiagenesis and telodiagenesis stages. During the eogenetic stage, carbonate cementation and mechanical compaction were the main processes. Mesodiagenesis is marked by chemical compaction, syntaxial quartz overgrowths, carbonate and sulfate cementation and clay minerals authigenesis. The deep burial, by long time or under high temperature conditions, characteristic of the mesodiagenetic stage, is interpreted from the packing proximity index ( $\mathrm{Pp} \mathrm{55)}$ and for the presence of concavousconvex and sutured contacts in the sandstones of the Itararé Group. Telodiagenetic stage is important in the outcrop units of the Itararé Group, where the dissolution was very intense, followed of fulfilling of the space generated for iron oxide. The diagenetics alterations affected the quality of the arenaceous reservoirs, mainly the reduction of the porosity for compacting.
\end{abstract}

Keywords: diagenesis, sandstones, Itararé Group, reservoirs.

INTRODUÇÃO O Grupo Itararé (Carbonífero-Permiano), da Bacia do Paraná, é caracterizado por unidades depositadas sob influência glacial, incluindo intervalos estratigráficos onde predominam arenitos, considerados reservatórios potenciais para hidrocarbonetos. Esses intervalos são constituídos por camadas de arenitos finos a conglomeráticos, que ocorrem associados com folhelhos e diamictitos.

Resultados exploratórios obtidos na Bacia do Paraná na década de 90 indicam que o sistema petrolífero Ponta Grossa (geradora) - Itararé (reservatório), apresenta bom potencial para gás e condensado. Segundo estes estudos, as acumulações ocorrem em reservatórios situados entre 3000 a $4600 \mathrm{~m}$ de profundidade. Contudo, as características que afetam a qualidade destes reservatórios são pouco conhecidas. Dentre os estudos existentes, merecem destaque os de França (1984), França (1987) e França \& Potter (1989). Nestes trabalhos vincula-se a qualidade dos reservatórios arenosos do Grupo Itararé com a ocorrência de porosidade secundária, gerada por dissolução de grãos e cimentos. Porém, a avaliação da qualidade de reservatório em função da porosidade secundária é um tópico polêmico em petrologia sedimentar clástica (Giles \& Marshall 1986; Giles 1987). Apesar de ser amplamente reconhecida, há controvérsias entre diversos autores quanto à importância da porosidade secundária para a predição da qualidade de reservatório.

O principal objetivo deste artigo é a apresentação de resultados de estudos petrográficos e discussão de aspectos diagenéticos modificadores da permo-porosidade original dos reservatórios arenosos do Grupo Itararé, Bacia do Paraná (sul do Brasil). Esta pesquisa foi realizada no âmbito do Projeto MODRES - Modelagem de Potenciais Reservatórios Fraturados em Superficie para Auxilio Exploratório em Subsuperficie, desenvolvido na Universidade Federal do Paraná com apoio da PETROBRAS - Petróleo Brasileiro S/A por intermédio do PROFEX, Programa Tecnológico em Fronteiras Exploratórias, em conjunto com a FINEP - Financiadora de Estudos e Projetos do Governo Brasileiro.

AMOSTRAGEM E MÉTODOS Foram examinadas 72 amostras de arenitos de superficie e 52 amostras de testemunhos de sondagem, impregnadas com resina e corante azul. A amostragem e análise dos dados de superfície foram realizadas considerando os modelos definidos em trabalhos anteriores (França \& Potter, 1991; Eyles et al, 1993; França et al, 1996; Rostirolla et al, 2001; Vesely et al, 2003, Appi \& Rostirolla, 2004). Os afloramentos estudados localizam-se nas imediações

I - UFPR - Departamento de Geologia - Laboratório de Análise de Bacias e Petrofísica, Caixa Postal 19027, CEP: 81531-990, Curitiba, PR. E-mail: Ibocardi@ufpr.br 2 - UFPR - Departamento de Geologia - Laboratório de Estudos Sedimentológicos, Caixa Postal 19001, CEP: 81531-990, Curitiba, PR. E-mail: lufernandes@ufpr.br 3 - UFPR - Departamento de Geologia - Laboratório de Análise de Bacias e Petrofisica, Caixa Postal 19027, CEP: 81531-990, Curitiba, PR. E-mail: rostirolla@ufpr.br 4 - PETROBRÁS - PROFEX - Cidade Universitária, Quadra 7, CEP: 21949-900, Rio de Janeiro, RJ.E-mail: appi@cenpes.petrobras.com.br 


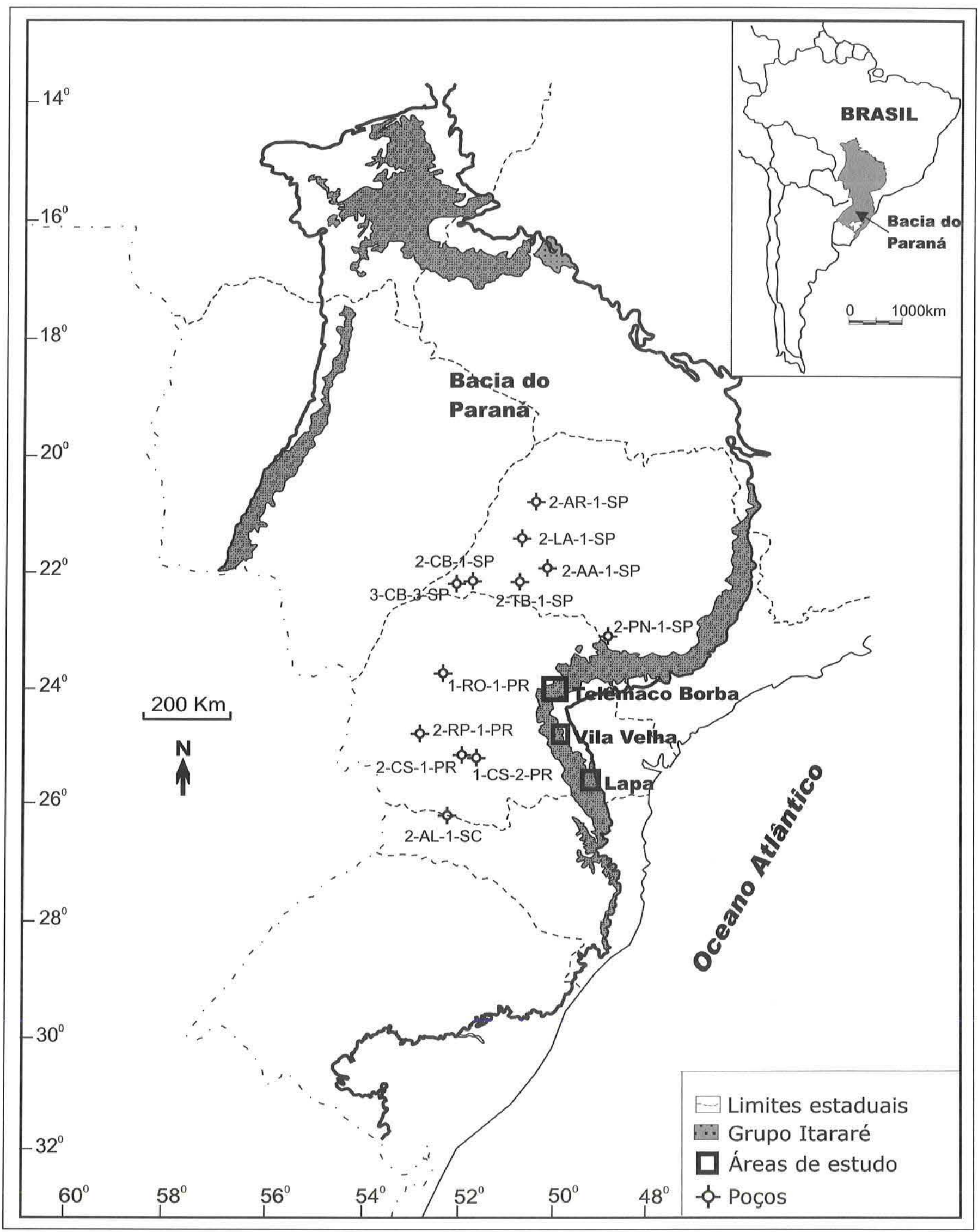

Figura 1. Localização da porção brasileira da Bacia do Paraná, com indicação das áreas onde foram realizados os perfis de superficie e localização dos testemunhos de sondagem utilizados.

do Parque Estadual de Vila Velha, na região de Telêmaco Borba e na região da Lapa, borda leste da Bacia do Paraná, no Estado do Paraná (Figura 1).

As amostras de subsuperficie foram selecionadas em teste- 


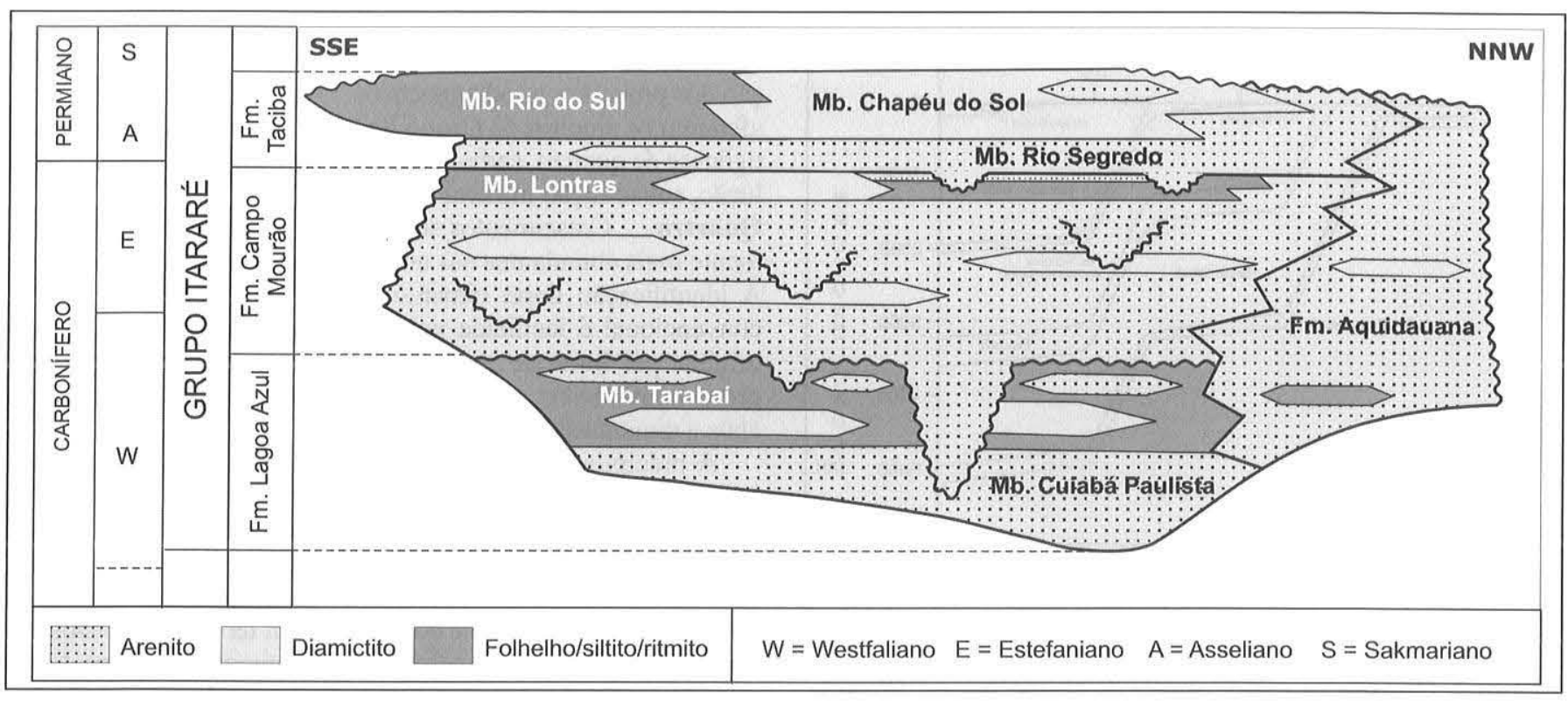

Figura 2. Carta estratigráfica do Grupo Itararé. França et al.(1996).

munhos dos poços da Petrobrás e Paulipetro. Representam um intervalo de profundidade entre $350 \mathrm{~m}$ a $4700 \mathrm{~m}$, mas a maioria das amostras provém dos intervalos mais profundos $(2300$ a $4700 \mathrm{~m})$.

Os componentes detríticos, constituintes diagenéticos e porosidade foram determinados por contagem de 300 pontos em 20 seções delgadas representativas. A determinação da porosidade foi auxiliada pela análise digital de imagens, com base em Ehrlich et al. (1984) e Anjos (1995). A porosidade original foi estimada a partir das características texturais de seleção dos grãos, conforme Beard \& Weyl (1973). Os poros secundários foram analisados segundo critérios propostos por Schmidt \& McDonald (1979 apud Wilson \& Stanton 1994).

A caracterização dos constituintes diagenéticos foi realizada com o uso de microscópio óptico de luz transmitida da marca Leica, dotado de câmera para captura de imagens digitais. Os argilominerais foram analisados com difração de raios $\mathrm{X}$, com o uso de difratômetro Philips PW 1830. Os resultados foram analisados com o uso do software High Score Xpert e do banco de dados JCPDS. A morfologia e relações entre os minerais em pequena escala foram examinadas com microscópio eletrônico de varredura (Philips XL30), com sistema de detecção de energia dispersiva de raios X (EDAX DX-4i) e interpretadas com auxílio do SEM Petrology Atlas (Welton 1984).

A importância relativa dos processos de compactação e cimentação na redução da porosidade foi quantificada usando-se gráficos de volume intergranular versus cimentação (Houseknecht, 1987). A interpretação da seqüência diagenética foi baseada nas regras de paragênese organizadas por De Ros \& Remus (2001). Os campos diagenéticos foram classificados em eodiagênese, mesodiagênese e telodiagênese (Schmidt \& McDonald 1979 apud Wilson \& Stanton 1994).

CONTEXTO GEOLÓGICO A Bacia do Paraná é uma bacia intracratônica com aproximadamente $1.600 .000 \mathrm{~km}^{2}$ localizada na América do Sul (Figura 1), formada em função da subsidência termal da crosta após múltiplas colisões durante o Ciclo Orogênico Brasiliano-Panafricano (Zalán et al. 1990). Seu preenchimento é constituído por aproximadamente $6.000 \mathrm{~m}$ de espessura de rochas sedimentares e vulcânicas, agrupadas em seis seqüências: Ordovício - Siluriano, Devoniano, Carbonífero
- Eotriássico, Neotriássico, Neojurássico - Eocretáceo e Neocretáceo (Milani \& Ramos, 1998). Fernandes \& Coimbra (1996) excluíram a seqüência neocretácea do registro sedimentar da Bacia do Paraná, por considera-la acumulada em uma nova bacia. As três primeiras seqüências correspondem a grandes ciclos transgressivos, enquanto as demais são representadas por sedimentação continental e rochas ígneas associadas.

O período de deposição dos sedimentos do Grupo Itararé situa-se entre o Neocarbonífero e o Eopermiano (Figura 2) e registra a influência de ambiente glacial na Bacia do Paraná. França \& Potter (1988) descreveram três ciclos deposicionais para este grupo, condicionados por avanços e recuos de geleiras. Estes ciclos correspondem às formações Lagoa Azul, Campo Mourão e Taciba e iniciam com a deposição de arenitos finos a grossos e culminam com a deposição de siltitos e diamictitos.

História de soterramento O embasamento da Bacia do Paraná, submetido a vários episódios orogênicos, apresentou um comportamento flexural. Este mecanismo permitiu a geração cíclica de espaço à sedimentação (Milani \& Thomaz Filho 2000). De acordo com Zalán et al. (1990) ocorreram três fases principais de subsidência na Bacia do Paraná (Siluriano-Devoniano, PermoCarbonífero e Jurássico/Cretáceo), separadas por períodos de erosão e não deposição ou por baixas taxas de sedimentação.

A história de soterramento do Grupo Itararé relaciona-se à segunda fase de subsidência da bacia e com sua evolução geotectônica a partir do Carbonífero-Permiano (Figura 3). Esta fase de subsidência é atribuída à sobrecarga das geleiras continentais, seguida pelo peso dos sedimentos depositados durante o ciclo transgressivo-regressivo subseqüente (Zalán et al. 1987). O término desta fase de sedimentação relaciona-se a um soerguimento generalizado, associado à Orogenia Finiherciniana (Zalán et al. 1987) ou Orogenia Sanrafaélica (Milani \& Ramos 1998).

Durante o Triássico e parte do Jurássico a razão de subsidência foi muito baixa na Bacia do Paraná. A terceira fase de subsidência (Neojurássico/Eocretáceo) ocorreu por sobrecarga, após o magmatismo basáltico. Este evento magmático teve duração estimada entre 8 e 11 Ma (Turner et al. 1994). A anomalia térmica desencadeada pelo afinamento crustal durante o rifteamento do Gondwana e abertura do Oceano Atlântico foi responsável pela maturação da matéria orgânica, presente nos folhelhos das rochas 


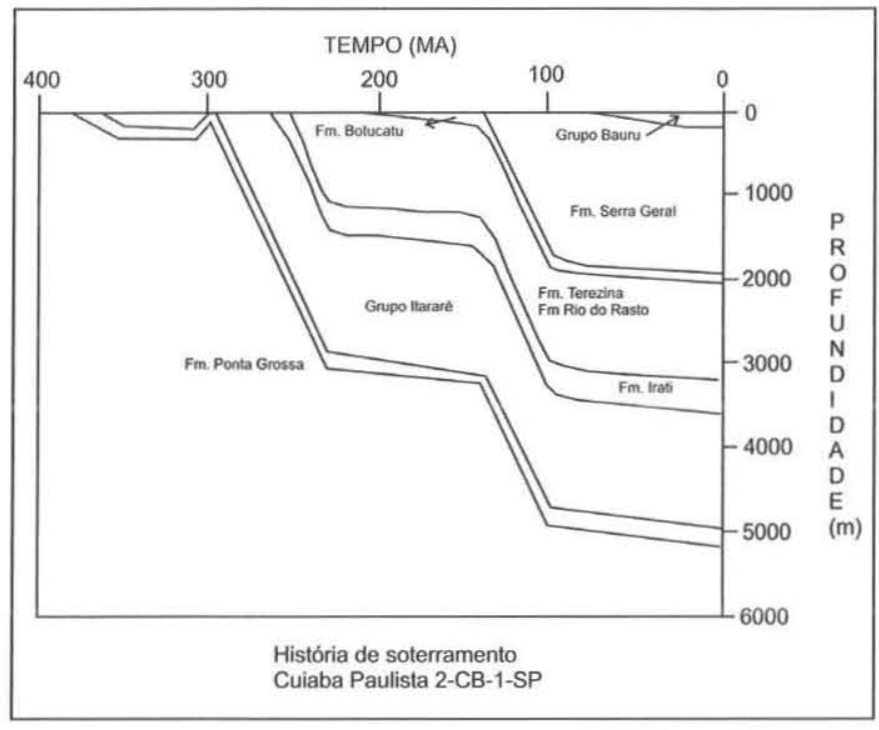

Figura 3. História de soterramento do Grupo Itararé (França, 1987).

geradoras e pelo desenvolvimento de porosidade secundária nas seqüências arenosas do Grupo Itararé (França \& Potter 1989).

A profundidade estimada de soterramento do Grupo Itararé, obtida pelo somatório da espessura das seqüências superiores é de $4075 \mathrm{~m}$ (perfil do poço 2-AN-1-PR), embora na parte central da Bacia do Paraná a profundidade de soterramento possa chegar a 5000m (França 1984).

Os limites atuais da Bacia do Paraná foram estabelecidos como conseqüência de soerguimentos decorrentes da interação de placas tectônicas durante a evolução da bacia. O soerguimento da Serra do Mar, que iniciou no Turoniano (Cretáceo Superior) e afetou a região sudeste do Brasil, provavelmente relaciona-se ao soerguimento e exposição do Grupo Itararé na borda leste da Bacia do Paraná.

\section{COMPOSIÇÃO DETRÍTICA E TEXTURA DOS ARENI-}

TOS Os arenitos que constituem o Grupo Itararé são muito heterogêneos quanto à composição detrítica e textura. Entre as principais características mineralógicas destacam-se: (1) arenitos de granulação fina à média, constituídos por quartzo, feldspatos e fragmentos líticos e (2) arenitos de granulação fina à média, constituídos essencialmente por quartzo. Em amostras de subsuperficie ocorrem principalmente sublitoarenitos e subarcóseos (segundo a classificação de Folk,1968). Em superficie os quartzoarenitos predominam (Figura 4).

$\mathrm{O}$ grau de arredondamento original foi influenciado por modificações diagenéticas, decorrentes da precipitação de sobrecrescimentos sintaxiais de quartzo e da dissolução por pressão ao longo dos contatos entre os grãos. Nas amostras onde se observa a delineação da forma original dos grãos por óxidos se evidencia bom arredondamento. Os grãos de quartzo são principalmente monocristalinos e freqüentemente encobertos por crescimentos sintaxiais de quartzo. Grãos policristalinos são localmente abundantes. A identificação do tipo de feldspato em amostras de superfície é difícil, em função da sua alteração. Os feldspatos mostram sinais de dissolução nas amostras de subsuperfície e freqüentemente são substituídos por anidrita. Os fragmentos líticos são constituídos por rochas metamórficas, plutônicas, vulcânicas e sedimentares, tais como arenitos e intraclastos argilosos.

CONSTITUINTES DIAGENÉTICOS As análises de amostras provenientes de testemunhos de sondagens fornecem dados mais completos para a interpretação das fases eodiagenética e mesodiagenética dos arenitos do Grupo Itararé. No entanto, as amostras de afloramentos foram importantes para caracterização dos processos telodiagenéticos. Os principais processos que afetaram os arenitos do Grupo Itararé foram a compactação, autigênese de quartzo, carbonatos, sulfatos e argilominerais, dissolução, substituição mineral e precipitação de óxidos.

Quartzo Crescimentos secundários de quartzo são relativamente mais abundantes nas amostras de superficie (Figura 5A). A identificação deste cimento através de microscopia óptica convencional é facilitada pela delineação do formato do grão original por filme de argila ou óxidos que marcam o contorno pré-cimentação em contraste com o contorno euédrico dos grãos após a cimentação (Figura 5B).

A precipitação de sílica antes de substancial compactação é sugerida pela sua forma contínua ao redor dos grãos, inclusive nas áreas de contatos intergranulares (Figura 5B). Porém, grandes volumes de constituintes intergranulares também podem ser relacionados à substituição de grãos. Desta forma, os crescimentos sintaxiais de quartzo podem ter sido formados em espaços gerados pela dissolução de um cimento anterior. Isto é sugerido pelas feições de corrosão ao longo dos contatos entre os grãos detríticos e os crescimentos sintaxiais.

Na maioria das amostras os crescimentos sintaxiais de quartzo são formados após intensa dissolução por pressão, evidenciado pela ausência de crescimento secundário de quartzo nos contatos intergranulares (Figura 5C). A formação de crescimentos secundários de quartzo em poros intergranulares ocorre com freqüência em amostras de subsuperfície. O desenvolvimento destas feições é comum na fase mesodiagenética (De Ros, 1998).

Estas características indicam pelo menos duas fases de cimentação por quartzo e sugerem que esta cimentação foi recorrente ao longo da evolução diagenética do Grupo Itararé.

Anidrita A cimentação por anidrita foi verificada na maioria das amostras provenientes de testemunhos de sondagens. Porém, apesar de ser abundante nas amostras em subsuperficie, não foi observada nas amostras de superfície. Cristais poiquilotópicos envolvendo vários grãos são comuns, porém ocorrem ainda como cristais menores, preenchendo espaços intergranulares.

Os grãos do arcabouço, principalmente quartzo detrítico, apresentam algumas vezes feições de corrosão no contato com cristais de anidrita. O contato entre os cristais de anidrita e os cimentos carbonáticos é reto e abrupto, sugerindo precipitação contemporânea, embora em algumas amostras observam-se cristais de anidrita englobando cristais de carbonato, indicando precipitação posterior. A precipitação de anidrita ocorre após a cimentação sintaxiais de quartzo. Isto é evidenciado pela corrosão em crescimentos sintaxiais de quartzo, no contato com anidrita (Figura 5D). A cimentação por anidrita é comum também como preenchimento de poros intragranulares em feldspatos, indicando precipitação após a substituição do mineral (Figura $5 \mathrm{E})$. A relação entre a precipitação de anidrita e os demais constituintes, sugere que a anidrita é um cimento tardio na evolução diagenética do Grupo Itararé.

Carbonatos A cimentação por carbonatos foi observada somente nas amostras de subsuperfície. Os carbonatos apresentam distribuição heterogênea, ocorrem como grandes cristais poiquilotópicos e também como cristais isolados. Calcita ocorre como grandes cristais, associada ao preenchimento de fraturas (Figura 5F).

Dolomita ferrosa ocorre na forma de pequenos cristais euédricos isolados (Figura 6A). Aparentemente foi precipitada em espaços intergranulares gerados após dissolução de cimento anterior. Isto é sugerido pela forma dos contatos entre os cristais e os poros de dissolução. Estes contatos são freqüentemente retos 


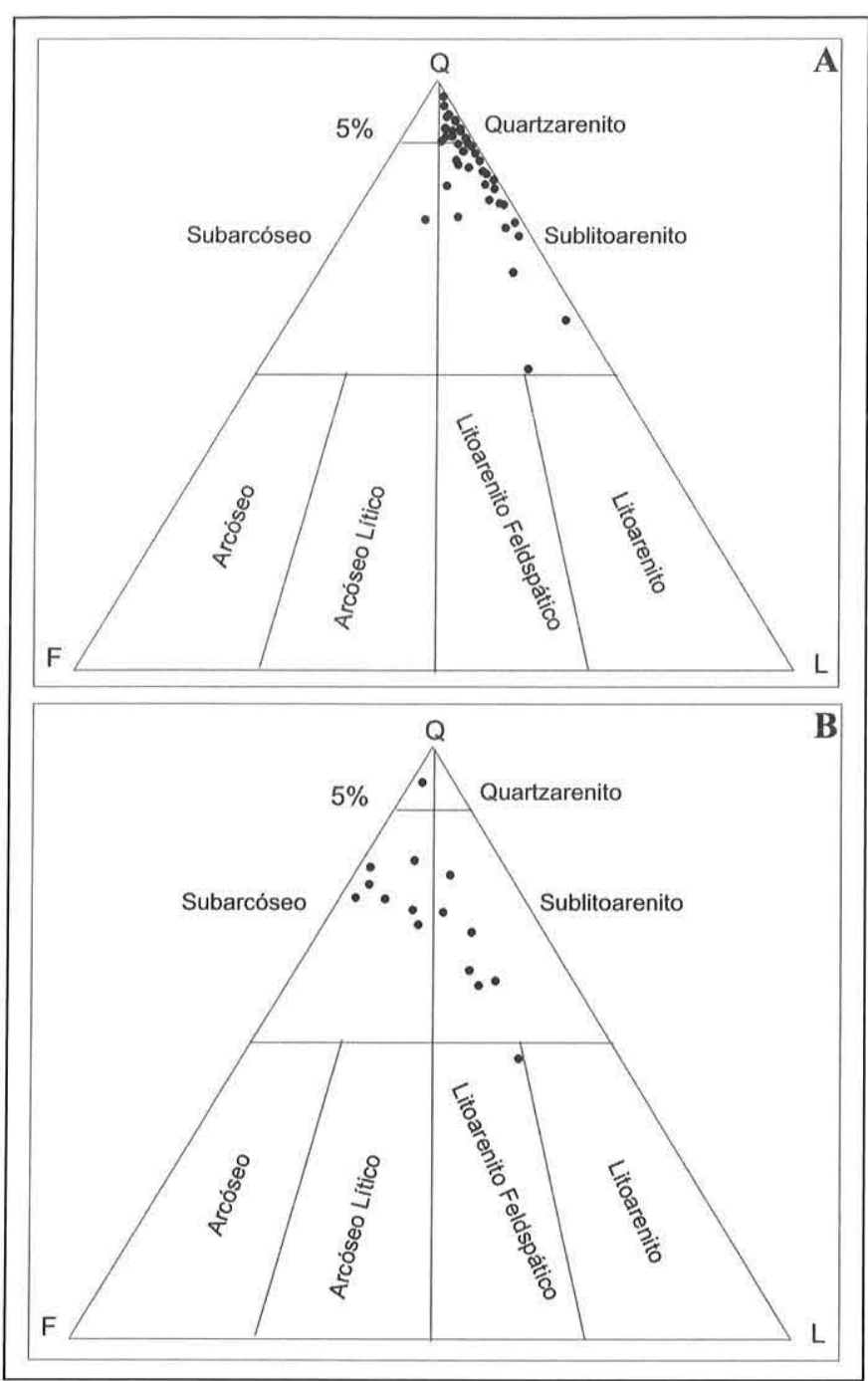

Figura 4 - Composição detritica dos arenitos do Grupo Itararé apresentadas no diagrama de Folk (1968). $Q=$ quartzo; $F=$ feldspato; $L=$ fragmentos líticos. $A$ - Classificação de 53 amostras de superficie, representativas da Formação Campo Mourão. B - Composição das amostras de testemunhos da Formação Campo Mourão.

\section{e bem marcados.}

A cimentação por siderita ocorre em algumas amostras, exibindo feições de dissolução parcial. As feições de dissolução podem ser observadas nos contatos entre remanescentes de cimento de siderita e os poros secundários. O contato entre siderita e os grãos constituintes do arcabouço indica que houve corrosão. Bordas de grãos irregulares corroídas e cimentos ocupando parcialmente os poros indicam dissolução tardia do cimento. Dissolução de siderita associada à clorita também é freqüente. Em seções delgadas observa-se a presença de siderita associada ao índice de empacotamento aberto, relacionada à fase pré-compactação. Isto é utilizado como uma evidência da precipitação precoce de siderita.

Argilominerais As análises realizadas indicam a ocorrência de caulinita autigênica nos arenitos do Grupo Itararé, de acordo com os critérios discutidos por De Ros \& Cesero (1986) e Fernandes et al. 1994.

Caulinita é freqüente nas amostras de superfície. A caulinita que recobre feldspatos ocorre como cristais com textura vermicular (Figura 6B). A caulinita intergranular é frequentemente dis- seminada nos poros e ocorre como provável produto da alteração de feldspato e fragmentos de argila. Na maioria das amostras de afloramento, poros secundários gerados por dissolução de feldspatos contêm caulinita autigênica. Nas amostras de subsuperfície (profundidade de $3087 \mathrm{~m}$ ), a caulinita com hábito pseudohexagonal euédrico ocorre associada à illita (Figura 6C).

Illita é comum nos arenitos do Grupo Itararé em amostras de superfície e em subsuperfície (profundidade 3074 m). Formam franjas perpendiculares, as quais contornam os grãos do arcabouço, principalmente os grãos de quartzo. Por meio de microscopia eletrônica de varredura (MEV) observam-se filamentos de illita autigênica (Figura 6D).

Clorita ocorre nas amostras provenientes de testemunhos de sondagem, principalmente na forma de rosetas preenchendo os poros dos arenitos em profundidades superiores a 2000m (Figura $6 \mathrm{E})$. Nos contatos entre clorita e crescimentos sintaxiais de quartzo observam-se feições de corrosão do quartzo, sugerindo que a precipitação de clorita ocorreu após a cimentação por crescimentos sintaxiais de quartzo. A cimentação por clorita é comum como preenchimento de poros de dissolução, indicando uma fase de precipitação tardia.

Esmectita autigênica foi observada em amostras de profundidade em torno de $2300 \mathrm{~m}$. Ocorrem na forma de cristais bem desenvolvidos, com aspecto crenulado. Geralmente estão associadas à illita e tendem a ser substituídas por estas.

Óxidos e hidróxidos Nas amostras de superfície, foram observadas duas fases de precipitação de óxidos de ferro.

A primeira fase é marcada pela precipitação de fina película de óxidos de ferro, delineando os grãos de quartzo, antes do desenvolvimento de crescimentos sintaxiais de quartzo (Figura 5B). Esta fase possivelmente relaciona-se ao início da diagênese.

$\mathrm{Na}$ segunda fase destaca-se intensa percolação de óxidos de ferro nos espaços intergranulares (Figura 6F). Estes espaços constituem poros de dissolução de cimentos ou grãos do arcabouço, indicados pelo contorno irregular dos grãos de quartzo, com aspecto de corrosão e pela forma dos poros. Estas relações de paragênese indicam que provavelmente havia um cimento nos espaços intergranulares, que foi dissolvido e posteriormente o espaço ocupado por óxidos de ferro.

Nas amostras de subsuperfície os óxidos são pouco comuns. Porém em um testemunho do poço 2-AR-1-SP, ocorre como cimento em amostras situadas a $2300 \mathrm{~m}$ de profundidade. Nestas amostras também se observa porosidade por dissolução de cimentos e preenchimento de parte do espaço intergranular por óxidos.

DISCUSSÃO Os arenitos do Grupo Itararé em superfície são dominantemente quartzarenitos. Amostras de subsuperfície constituem-se de quartzoarenitos, subarcóseos e sublitoarenitos. Alguns autores sugerem que arenitos quartzosos são multicíclicos ou depositados sob alta abrasão em ambientes de praias ou eólicos (Pettijon et al, 1987; De Ros, 1998). Vesely et al. (2004), propuseram deposição em ambiente de alta energia sob ação de ondas para quartzoarenitos do Grupo Itararé, presentes na área de Vila Velha. Contudo, a abundância de quartzoarenitos em amostras de afloramento pode ser resultante de processos diagenéticos, desenvolvidos a partir da alteração de fragmentos de rocha e feldspatos por dissolução e substituição. Uma tentativa de reconstrução da composição original dos arenitos, através da contagem dos poros móldicos como constituintes nas amostras de superfície e da comparação entre amostras do Grupo Itararé nos intervalos correlatos em superfície e subsuperfície, sugere que sublitoarenitos e subarcóseos foram transformados em quartzoarenitos diagenéticos por extensiva dissolução, caolinização e illitização de grãos de feldspatos.

As relações paragenéticas foram interpretadas a partir da in- 

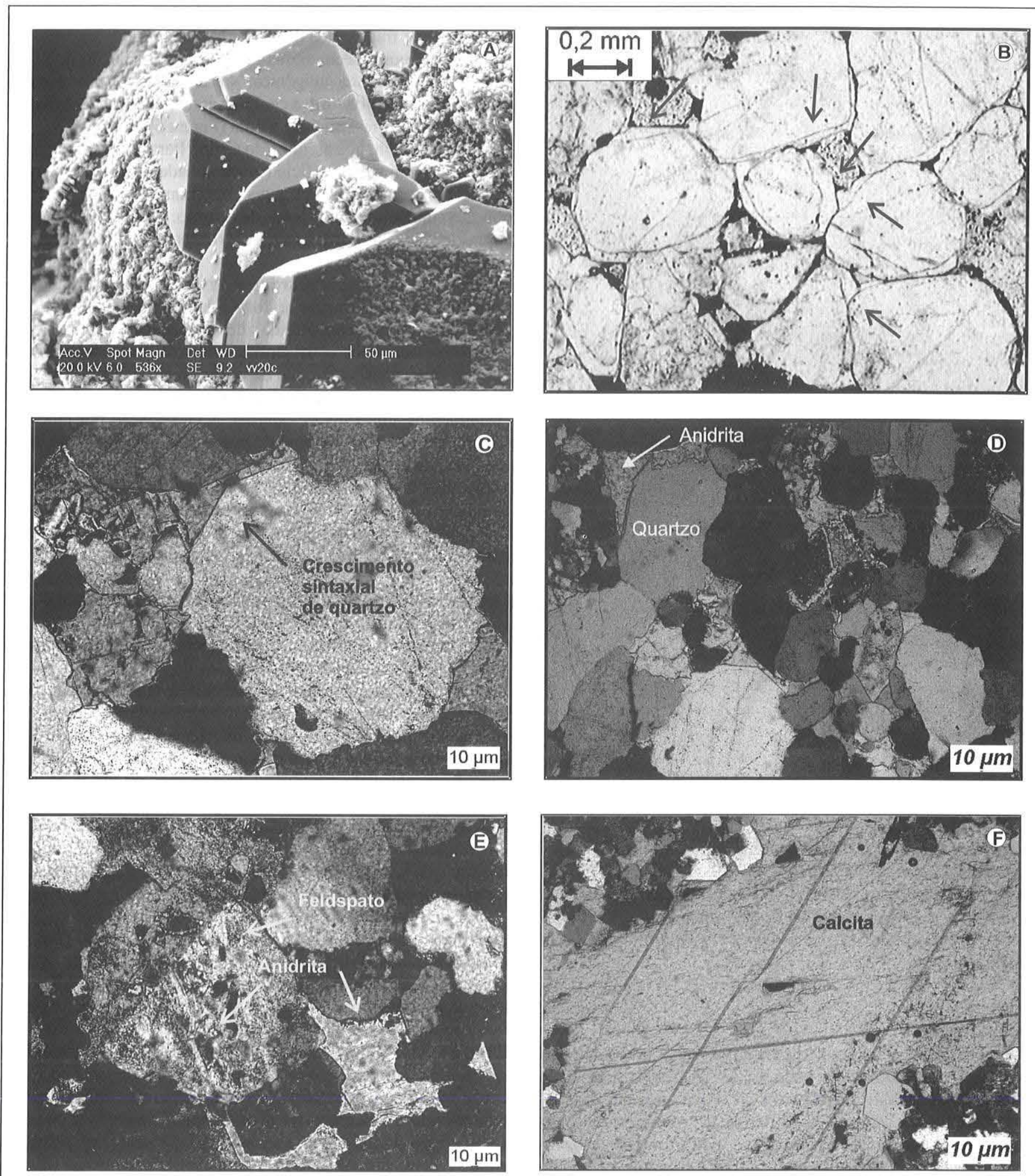

Figura 5. (A) Crescimento sintaxial de quartzo (imagem de MEV, elétrons secundários). Amostra Te20, de superficie (B) Crescimentos sintaxiais de quartzo contínuos ao redor dos grãos. Ocorrem em algumas áreas de contatos intergranulares. Observa-se o contorno do grão original marcado por filme de óxidos. Amostra Rl, de superficie. (C) Crescimentos sintaxiais de quartzo precipitados após intensa dissolução por pressão. Amostra 4CB, profundidade de $3786 \mathrm{~m}$. (D) Corrosão de crescimento sintaxial de quartzo em contato com anidrita. (E) Substituição de feldspato por anidrita. Amostra 3CB, 3785m de profundidade. (F) Calcita associada ao preenchimento de fraturas. Amostra 42CS, profundidade de $3105 \mathrm{~m}$.

tegração dos dados obtidos. Contudo, devido à complexidade dos processos diagenéticos e à ausência de dados geotermométricos, o tempo preciso não pode ser determinado para todos os efeitos diagenéticos observados.
Os principais processos que afetaram os arenitos do Grupo Itararé foram a compactação mecânica e química, autigênse de quartzo, carbonatos, sulfatos e argilominerais, dissolução, substituição mineral e precipitação de óxidos. Os estágios diagené- 

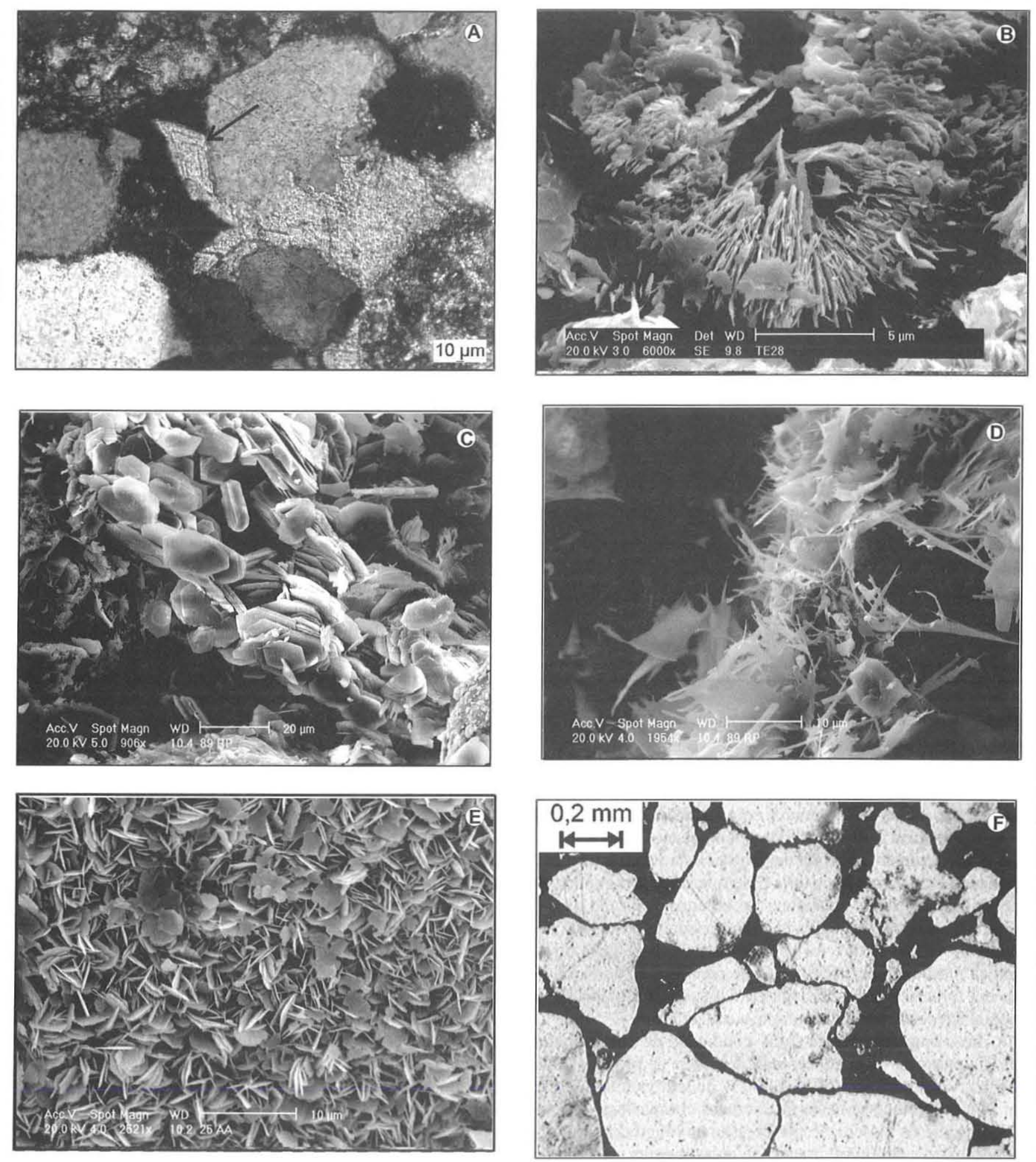

Figura 6. (A) Dolomita ferrosa, na forma de pequenos cristais euédricos. Amostra 88RP, profundidade de $3082 \mathrm{~m}$. (B) Caulinita em forma de cristais vermiculares. Amostra Te20 de superficie. (C) Caulinita com hábito pseudohexagonal, euédrico associada a illita. Amostra 89RP, profundidade de $3087 \mathrm{~m}$. (D) Filamentos de illita observados por meio de microscopia eletrônica de varredura (MEV). Amostra 89 RP, profundidade 3074m. (E) Clorita observada por meio de microscopia eletrônica de varredura $(M E V)$. Amostra 25AA, profundidade de $2292 \mathrm{~m}$. (F) Intensa precipitação de óxidos de ferro nos espaços intergranulares. Amostra R2, em superficie.

ticos foram relacionados a uma curva de soterramento esquemática, elaborada a partir da curva de soterramento obtida por França (1987), com base nos dados do poço Cuiabá Paulista, 2-CB-1-SP. (Figura 7).
A eodiagênese relaciona-se aos processos controlados pelo ambiente deposicional , atuantes desde próximo a superfície até cerca de $1 \mathrm{~km}$ de profundidade e temperatura em torno de $50^{\circ} \mathrm{C}$ (Wahab 1998). A siderita que ocorre como cimento entre os grãos 


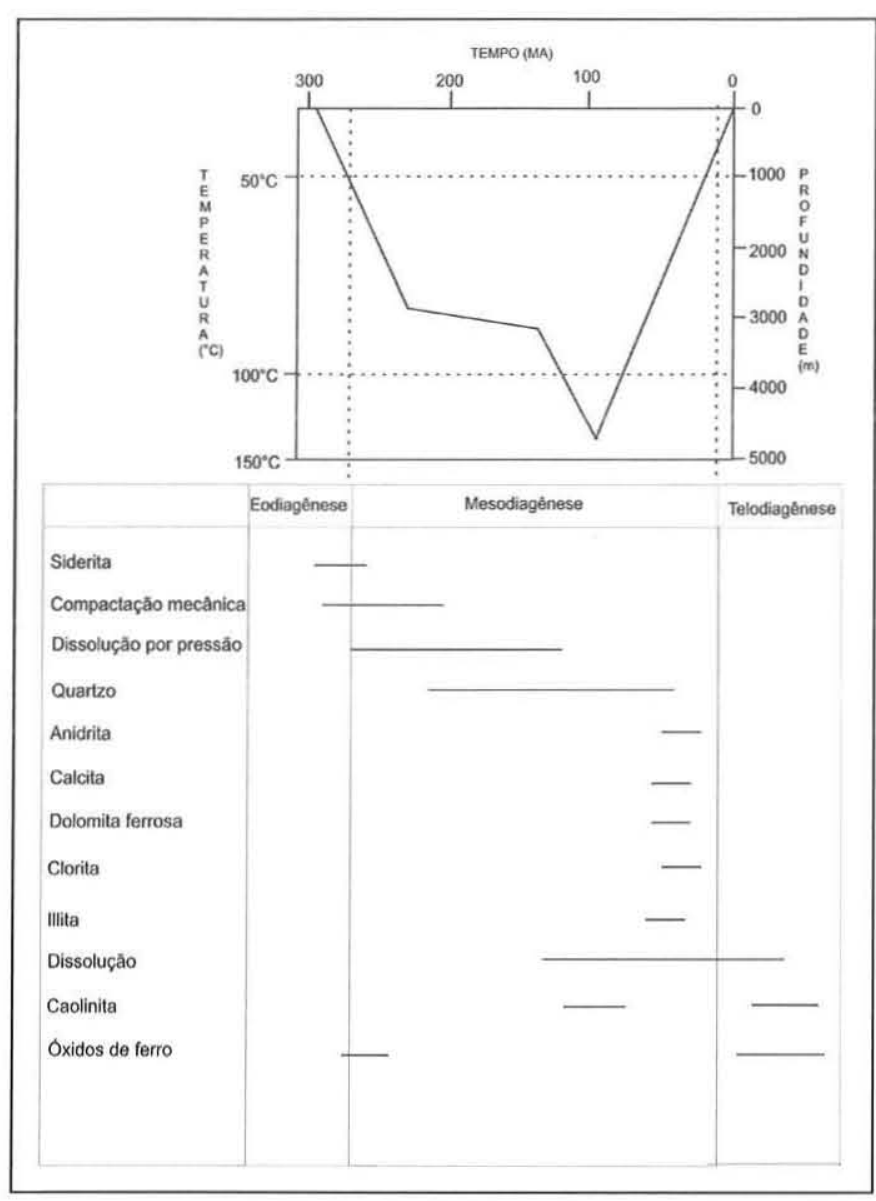

Figura 7. Curva esquemática de soterramento, relacionada aos estágios e produtos diagenéticos.

do arcabouço, antes de substancial compactação, é relacionada a esta fase. França \& Potter (1989) também relacionaram a cimentação por siderita ao início da diagênese. Esta precipitação precoce de cimento carbonático teria desempenhado um importante papel na sustentação do arcabouço nos arenitos do Grupo Itararé. Os autores atribuem que a porosidade secundária observada nos arenitos do Grupo Itararé foi promovida pela dissolução de siderita na mesodiagênese. Uma fase de precipitação de óxido de ferro em torno dos grãos de quartzo é associada à oxidação de minerais ferro-magnesianos durante a eodiagênese.

A mesodiagênese refere-se às condições de soterramento efetivo a partir de $1 \mathrm{~km}$ até cerca de 5 a $7 \mathrm{~km}$ de profundidade, abrangendo variações de $50^{\circ} \mathrm{C}$ a $200^{\circ} \mathrm{C}$ de temperatura (Morad et al.2000). Destaca-se nesta fase intensa compactação química, decorrente da dissolução por pressão ao longo dos contatos intergranulares, desenvolvimento de crescimentos secundários de quartzo, precipitação de carbonatos, sulfatos, argilominerais e dissolução.

A cimentação por sílica nos arenitos do Grupo Itararé aparentemente foi incipiente durante a eodiagênese e mais expressiva durante a mesodiagênese.

A maioria dos modelos de cimentação por sílica refere-se a bacias profundas que sofreram subsidência rápida (De Ros 1998). Nestas bacias a cimentação por quartzo aumenta sistematicamente com a profundidade. Dados de inclusões fluidas em quartzo sugerem que a sílica foi precipitada a temperaturas em torno de $100^{\circ} \mathrm{C}$, em profundidade de soterramento superior a 2 a 3 km (Bjørlykke \& Egeberg 1993). Neste modelo a cimentação por sílica desenvolve-se basicamente através de difusão, por dissolução por pressão ao longo dos contatos intergranu- lares. Outros autores consideram que a cimentação por quartzo é episódica, relacionada ao rifteamento e circulação de fluidos quentes através das falhas (Glasmann et al. 1989).

Segundo Wilson \& Stanton (1994), em escala regional, a dissolução por pressão é a única fonte volumetricamente adequada para explicar a cimentação por quartzo em arenitos. A dissolução por pressão intergranular parece ter sido uma importante fonte de sílica para cimentação de quartzo nos arenitos do Grupo Itararé. Contatos suturados decorrentes da dissolução por pressão de quartzo detrítico ocorrem freqüentemente associados aos crecimentos sintaxiais de quartzo.

A illitização de esmectitas em folhelhos subjacentes ou adjacentes é outra fonte de sílica utilizada para explicar a cimentação de quartzo em arenitos (Lynch 1996). Porém, alguns estudos indicam que a exportação de sílica dos folhelhos para os arenitos durante a diagênese ocorre por difusão a pequenas distâncias (Bjørlykke \& Egeberg 1993). No Grupo Itararé as reações de illitização nos folhelhos próximos aos arenitos podem ter sido importantes fontes de sílica para cimentação de quartzo, em função das espessuras e disposição estratigráfica dos folhelhos e diamictitos associados.

De Ros (1998) relacionou os grandes volumes e a distribuição heterogênea da cimentação por quartzo nos arenitos da Formação Furnas (Siluriano-Devoniano) na Bacia do Paraná ao transporte de sílica por convecção termobárica, decorrente do extensivo magmatismo ao longo do Arco de Ponta Grossa. Neste modelo considera-se que o incremento do fluxo de fluidos devido à intrusão de magma basáltico poderia induzir atividade de convecção de fluidos através de falhas e fraturas reativadas pelo soerguimento do arco. Esta fonte de sílica para cimentação de quartzo provavelmente relaciona-se a cimentação tardia na forma de sobrecrescimentos de quartzo bem desenvolvidos, observados nos arenitos do Grupo Itararé.

As relações paragenéticas observadas sugerem que a precipitação de anidrita ocorreu no estágio mesodiagenético. As principais fontes para cimentação de anidrita relacionam-se a evaporitos associados ou vulcanismo (De Ros \& Remus, 2001). Os carbonatos também foram relacionados ao estágio mesodiagenético. Calcita ocorre principalmente preenchendo fraturas e dolomita ferrosa em poros de dissolução.

Os principais argilominerais relacionados à mesodiagênese são clorita, illita e caulinita. Clorita é característica de ambientes ricos em ferro e magnésio, originando-se na mesodiagênese, a partir transformações de minerais ferromagnesianos e esmectitas (De Ros \& Remus 2001). A partir das relações paragenéticas observadas entre crescimentos sintaxias de quartzo e clorita nos arenitos do Grupo Itararé, verificou-se que a formação de clorita relaciona-se à mesodiagênese, sob condições de soterramento profundo e é posterior à cimentação de quartzo. Isto é indicado pelo recobrimento de fases de crescimento sintaxial de quartzo por clorita.

A illita autigênica é formada a partir de reação isoquímica entre a caulinita e feldspato potássico, favorecida por altas temperaturas e baixa permeabilidade sob condições de soterramento profundo (Bjørkum \& Gjelsvik 1988). A ocorrência de illita nos arenitos do Grupo Itararé, em profundidade moderada, pode ser explicada por este modelo, que não se aplica, entretanto, para explicar a ocorrência de illita nas amostras de superfície. De Ros (1998) relacionou a ocorrência de illita, presente em amostras de profundidade rasa na Formação Furnas, ao auge das atividades do vulcanismo basáltico na Bacia do Paraná. A precipitação de illita foi associada à circulação de fluidos quentes através de fraturas reativadas com o magmatismo e soerguimento do Arco de Ponta Grossa.

Esmectita é característica de ambientes com abundância de íns provenientes de alteração de fragmentos de rocha vulcânica, 
os quais ocorrem com freqüência nos arenitos do Grupo Itararé. Tendem a ser substituídas por illita ou clorita na mesodiagênese.

Caulinita com morfologia pseudohexagonal ocorre em amostras provenientes de testemunhos (profundidade de 3087 m). Esta forma de ocorrência relaciona-se a substituição de caulinita com textura vermicular sob condições de soterramento profundo e temperaturas entre a $80^{\circ} \mathrm{C}$ a $130^{\circ} \mathrm{C}$ (Morad et al. 1994). Este processo é promovido por deficiência em potássio ou sob condições ácidas, relacionadas à maturação da matéria orgânica (Ehrenberg 1991).

A dissolução de feldspatos, carbonatos e sulfatos é um processo importante durante a mesodiagênese. Os mecanismos mais utilizados para explicar a dissolução em arenitos durante a mesodiagênese incluem, o dióxido de carbono gerado como produto da maturação termal orgânica e as reações com ácidos carboxílicos durante a maturação termal da matéria orgânica (Bloch 1994).

$\mathrm{O}$ estágio telodiagenético ocorre quando seqüências sedimentares que foram submetidas a eodiagênese e mesodiagênese são soerguidas e sofrem influência de fluidos meteóricos. Esta condição é observada nas rochas do Grupo Itararé que afloram da borda leste de Bacia do Paraná

As modificações telodiagenéticas mais importantes produzidas pelo fluxo de água meteórica nas unidades siliciclásticas incluem a dissolução de minerais, em geral de feldspatos, fragmentos líticos e cimentos instáveis (Morad et al. 2000). Nas amostras estudadas de superfície a dissolução é muito intensa, seguida de preenchimento do espaço gerado por óxido de ferro, impossibilitando muitas vezes a identificação dos minerais precursores. Nestas amostras, clorita e carbonatos ferrosos não foram observados, porém estes ocorrem nas amostras de subsuperficie indicando que devem ter sido alterados posteriormente. Isto é sugerido ainda pela quantidade de óxidos disseminada nos espaços intergranulares.

A dissolução dos cimentos eodiagenéticos e mesodiagenéticos como carbonatos e sulfatos é bastante significativa nos arenitos do Grupo Itararé. O mecanismo mais comum utilizado para explicar a dissolução de grãos e cimentos em arenitos na telodiagênese é o fluxo de água meteórica (Bloch 1994). A dissolução dos feldspatos ocorre usualmente a partir de clivagens e planos de fraturas. Estas características indicam ação de processos superficiais, sob baixa temperatura. Nas amostras de superficie a alteração de feldspato foi acompanhada pela neoformação de caulinita.

A caulinita que ocorre nas amostras de superfície é constituída por finas lamelas com cunhas irregulares na forma de agregados vermiculares. Esta forma de ocorrência indica condições de formação sob influência de fluxos meteóricos em profundidades rasas (Fernandes et al. 1994; De Ros, 1998). Nestes casos a caulinita foi possivelmente formada a partir de íons fornecidos pela alteração de grãos instáveis como feldspatos, micas e clastos de argila, em função das modificações telodiagenéticas em superfície.

Processos de redução da porosidade O sistema poroso dos arenitos do Grupo Itararé foi fortemente influenciado pela dissolução por pressão, devido ao soterramento no estágio mesodiagenético. Isto é indicado pela freqüência de contatos suturados, principalmente nas rochas constituídas essencialmente por quartzo. Os índices de fechamento ou de proximidade (Kahn 1956), evidenciam que o empacotamento é em geral fechado $(\mathrm{P}>55)$. O empacotamento normal $(40<\mathrm{P}<55)$, observado em algumas amostras, ocorre devido à dissolução de minerais instáveis em sublitoarenitos e subarcóseos. Esta interpretação é sugerida pela observação em seções delgadas de porções com empacotamento aberto, ocasionado por dissolução, ao lado de feições relacionadas com intensa compactação química e empacotamento fechado.

Outro aspecto que contribuiu para redução da porosidade

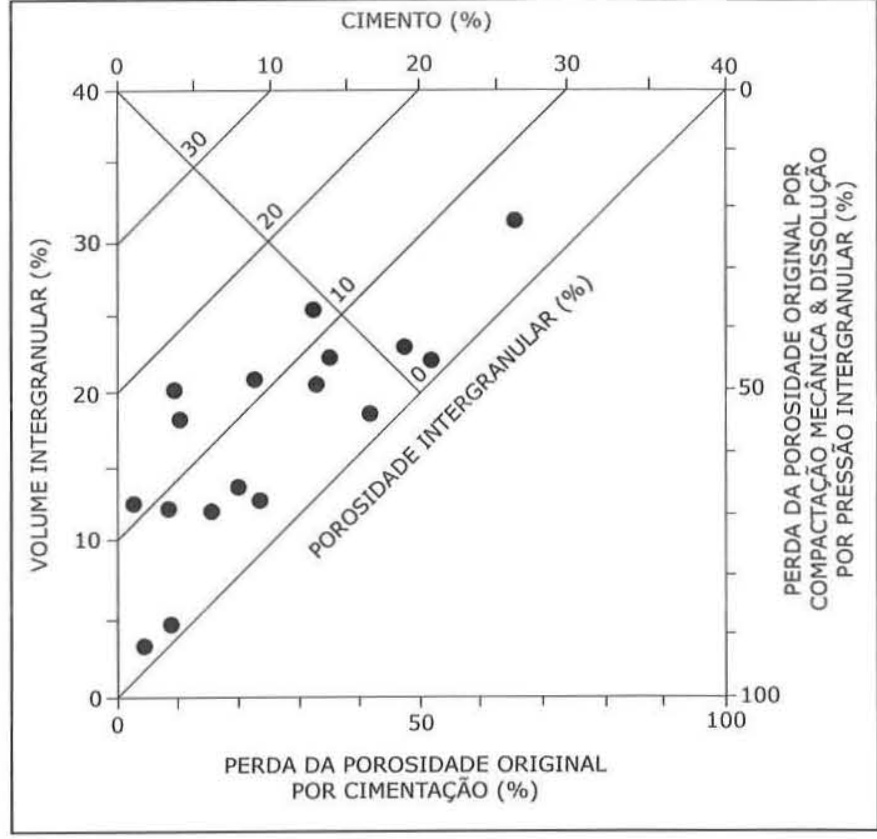

Figura 8. Gráfico para avaliação da importância relativa da cimentação e da compactação na perda de porosidade em arenitos (Houseknecht 1987).

nestas rochas foi a cimentação por crescimento sintaxial de quartzo, bem desenvolvida principalmente em quartzoarenitos de granulação média a grossa. Em alguns casos, a cimentação por crescimento sintaxial de quartzo, obstrui quase que totalmente o espaço intergranular.

A porosidade é principalmente secundária, gerada pela dissolução de grãos instáveis e de cimentos. Os principais critérios utilizados para reconhecimento de poros secundários tais como grãos corroídos, dissolução parcial de grãos detríticos (representados em geral por bordas marcadas por óxido de ferro, assim como poros anormalmente grandes que formam moldes de grãos detríticos), ocorrem em praticamente todas as amostras analisadas. Porém, a predição da qualidade de reservatório com base na porosidade secundária é difícil, uma vez que o aumento de porosidade pode estar relacionado à escala de observação em seção delgada e não representar o reservatório como um todo.

A importância relativa dos processos de compactação e de cimentação na redução da porosidade pode ser verificada com a utilização do gráfico de volume intergranular versus cimentação (Houseknecht 1987). Observa-se que a compactação foi mais importante que a cimentação na redução da porosidade (Figura 8). A redução de porosidade por compactação apresenta um aspecto irreversível na diminuição do sistema poroso e na geometria dos poros. Enquanto que a cimentação poderia atuar na preservação do arcabouço durante o soterramento e posteriormente favorecer um ganho de porosidade por dissolução, a compactação inibe reações diagenéticas posteriores.

CONCLUSÕES Os principais processos diagenéticos observados no estudo de arenitos do Grupo Itararé foram a compactação mecânica e química, autigênese de quartzo, carbonatos, sulfatos e argilominerais, dissolução, substituição mineral e precipitação de óxidos. No estágio eodiagenético destaca-se a cimentação carbonática e a compactação mecânica. Na mesodiagênese ocorre significativa compactação química, crescimentos sintaxiais de quartzo, cimentação por anidrita, dissolução parcial de cimentos e minerais instáveis, principalmente feldspatos e a substituição de grãos por carbonatos e sulfatos. $\mathrm{Na}$ 
telodiagênese destaca-se a dissolução de minerais e cimentos e a precipitação de óxidos de ferro.

A compactação desempenhou um papel fundamental na redução da porosidade, tendo em vista o aspecto irreversível na diminuição do sistema poroso e na geometria dos poros.

Nas rochas constituídas essencialmente por quartzo, o sistema poroso é fortemente influenciado pela dissolução por pressão, ao longo dos contatos, além da cimentação por sílica. Nestas condições a perda de porosidade tende a ser irreversível. A sílica precipitada como cimento sintaxial em torno dos grãos de quartzo é mais estável e pouco susceptível à dissolução posterior e a compactação química tende a ser mais eficiente.

Nos sublitoarenitos e subarcóseos a porosidade, em escala de seção delgada, é principalmente secundária, gerada pela dissolu- ção de grãos ou cimentos. Porém, a redução de porosidade por compactação é um aspecto considerável, em função do seu impacto na obliteração do sistema poroso e na geometria dos poros.

Agradecimentos À PETROBRAS - Petróleo Brasileiro S/A por intermédio do PROFEX, Programa Tecnológico em Fronteiras Exploratórias, em conjunto com a FINEP - Financiadora de Estudos e Projetos do Governo Brasileiro pelo apoio ao Projeto MODRES - Modelagem de Potenciais Reservatórios Fraturados em Superficie para Auxílio Exploratório em Subsuperficie. À UFPR pelo apoio institucional. Ao Dr. Almério B. França pelas discussões e empréstimo das seções delgadas de subsuperfície. Aos revisores da RBG pelas sugestões.

\section{Referências}

Anjos S.M.C. 1995. Análise de imagens no estudo do sistema poroso de rochas reservatório. Boletim Geociências Petrobrás, 9: (2/4):157173.

Appi C.J. \& Rostirolla S.P. 2004. Modelagem da anisotropia em sistemas fraturados a partir de estudos de alta resolução na Bacia do $\mathrm{Pa}$ raná, Brasil. Boletim de Geociências da Petrobrás, 12(1):125-147.

Beard D.C. \& Weyl P.K. 1973. Infuence of texture on porosity and permeability of unconsolidated sand. American Association of Petroleum Geologists Bulletin, 57:349-369.

Bjørkum P.A. \& Gjesvik N. 1988. An isochemical model for formation of autthigenic kaolinite, k-feldpar and illite in sediments. Journal of Sedimentary Petrology, 58:506-511.

Bjørlykke K. \& Egeberg P.K. 1983. Quartz cementation in sedimentary basins. American Association of Petroleum Geologists Bulletin, 77:1538-1548.

Bloch S. 1994. Secondary porosity in sandstones: significance, origin, relationship to subaerial unconformities, and effect on predrill reservoir quality prediction. Reservoir quality assessment and prediction in clastic rocks. Short Course 30, Tulsa, Oklahoma, SEPM, Society for Sedimentary Geology, pp.: 137-159.

De Ros L.F \& Cesero P. 1986. Argila em arenitos - Bases para a interpretação petrogenética. In: SBG, Cong. Bras. Geol. Goiânia, 34, Atas, 4:1663-1671.

De Ros L.F. 1998. Heterogeneous generation and evolution of diagenetic quartzarenites in the Siluro-Devonian Furnas Formation of the Paraná Basin, Southern Brazil. Sedimentary Geology, 116:99-128.

De Ros L.F. \& Remus, M.V.D. 2001. Petrologia das rochas siliciclásticas. Apostila do Curso. Estratigrafia e geoquímica, UFRGS, Porto Alegre, 96p.

Ehrenberg S.N. 1991. Kaolinized, potassium-leached zones at the contacts of the Garn Formation, Haltenbanken, mid-Norwegian continental shelf. Marine and Petroleum Geology, 8:250-269.

Ehrlich R.S.K., Kennedy, S.J. Crabtree, R.L. Cannon.1984. Photographic image analysis, I: Analysis of reservoir pore complexes. Journal of Sedimentary Petrology, 54:1365-1378.

Eyles C.H., Eyles N., França A.B. 1993. Glaciation and tectonics in an active intracratonic basin: the Late Palaeozoic Itararé Group, Paraná Basin, Brazil. Sedimentology, 40:1-25.

Fernandes L.A., Coimbra A.M., Brandt Neto, M. Gesicki, A.L.D. 1994. Argilominerais do Grupo Caiuá. Revista Brasileira de Geociências, 24:90-96.

Fernandes L.A. \& Coimbra A.M. 1996. A Bacia Bauru (Cretáceo Superior, Brasil). Anais Academia Brasileira de Ciências, 68:195-205.

Folk R. L. 1968. Petrology of sedimentary rocks. Austin, TX: Hemphill, $107 \mathrm{p}$.

França, A.B. 1984. Porosidade secundária nos arenitos das Formações Rio Bonito e Itararé e sua possível implicação na exploração de petróleo na Bacia do Paraná. Revista Brasileira de Geociências, $14(1): 35-46$.

França A.B. 1987. Stratigraphy, depzzhzosicional environment, and reservoir analysis of the Itararé Group (Permo-Carboniferous), Pa- raná Basin-Brazil. Dissertation submitted to the Division of Graduate studies and Research of the University of Cincinnati. 188p.

França A.B. \& Potter P.E. 1988. Estratigrafia, ambiente deposicional e análise de reservatório do Grupo Itararé (Permocarbonífero), Bacia do Paraná (Parte 1). Boletim Geociencias Petrobrás, 2:147-191.

França A.B. \& Potter P.E. 1989. Estratigra.a, ambiente deposicional do Grupo Itararé (Permocarbonífero), Bacia do Paraná (Parte 2). Boletim Geociências Petrobrás, 3:17-28.

França A.B. \& Potter P.E. 1991. Stratigraphy and reservoir potential of glacial deposits of the Itararé Group (Carboniferous-Permian), Paraná Basin, Brazil. American Association of Petroleum Geologists Bulletin, 75:62-85.

França A.B., Winter W.R., Assine M.L. 1996. Arenitos Lapa-Vila Velha: um modelo de sistemas subaquosos canal-lobos sob influência glacial, Grupo Itararé (C-P), Bacia do Paraná. Revista Brasileira de Geociências, 26(1): 43-56.

Giles M.R. \& Marshall J.D. 1986. Constraints on the development of secondary porosity in the subsurface: re-evaluation of processes. Marine and Petroleum Geology, 3:243-255.

Giles, M.R., 1987. Mass transfer and problems of secondary porosity creation in deeply buried hydrocarbon reservoirs. Marine and Petroleum Geology, 4:188-204

Glasmann J.R., Clark R.A., Larter S., Briedis N.A., Lundegard P.D. 1989. Diagenesis and hydrocarbon accumulation, Brent Sandstones (Jurassic). Bergen High, North Sea. American Association of Petroleum Geologists, Bulletin. 73:1341-1360.

Houseknecht D.W. 1987. Assessing the relative importance of compaction processes and cementation to reduction of porosity in sandstones. American Association of Petroleum Geologists Bulletin, 71:633-642.

Kahn J.S. 1956. The analysis and distribuition of the properties of packing in sand-size sediments. 1. On the measurement of packing in sandstones. Journal of Geology, 64:385-395.

Lynch F.L. 1996. Mineral/water interction, fluid flow, and Frio Sandstone diagenesis: evidence fron the rocks. American Association of Petroleum Geologists Bulletin, 80:486-504.

Milani J.E. \& Ramos V.A. 1998. Orogenias Paleozóicas no Domínio Sul-Ocidental do Gondwana e os Ciclos de Subsidência da Bacia do Paraná. Revista Brasileira de Geociências. 28(4):473-484.

Milani E.J. \& Thomaz Filho A. 2000. Sedimentary Basins of South America. In: U.G. Cordani; E.J. Milani, A. Thomaz Filho, D.A. Campos. Tectonic Evolution of South America, Edição Especial do 31st International Geological Congress, p. 389-449

Morad S., Ben Ismail H.N., De Ros L.F., Al-Aasm I.S., Serrhini N.E. 1994. Diagenesis and formation water chemistry of Triassic reservoir sandstones from southern Tunisia. Sedimentology, 41:12531272.

Morad S., Ketzer J.M., De Ros L.F. 2000. Spatial and temporal distribution of diagenetic alterations in siliciclastic rocks: implications for mass transfer in sedimentary basins. Sedimentology, 47:1-27.

Pettijohn F.J., Potter P.E., Siever R. 1987. Sand and sandstones. 2nd ed, 
Springer-Verlag, New York, 533p.

Rostirolla S.P., Appi C.J., Mancini F., Kraft R.P., Bartoszeck M.K. 2001. Fraturas controladoras da migração de fluidos nos Arenitos Vila Velha, Grupo Itararé, Bacia do Paraná. Revista Brasileira de Geociências, 31(3): 349-356.

Turner S., Regelous M., Kelley S., Hawkesworth C., Mantovani M. 1994. Magmatism and continental break-up in the South Atlantic: high precision $\mathrm{Ar} / \mathrm{Ar}$ geocronology. Earth and planetary Science Letters, 121:333-348.

Vesely F.F., Trzaskos-Lipski B., Kraft R.P., Rostirolla S.P., Appi C.J. 2003. Facies architecture of a Permocarboniferous sandstone reservoir analogue, Itararé Group, Paraná Basin, Brazil. in: Latinamerican Congress of Sedimentology, 3, Belém, Atas, p.197-198.

Vesely F.F., Rostirolla S.P., Appi C.J., Kraft R.P. 2004. Facies analysis and high resolution Sequence Stratigraphy applied to Late Paleozoic reservoirs of the Ponta Grossa - Itararé petroleum system, Paraná basin, Brazil. Marine and Petroleum Geology (submetido).

Wahab A.A. 1998. Diagenetic history of Cambrian quartzarenites, Ras Dib-Zeit Bay area, Gulf of Suez, eastern desert, Egypt. Sedimenta- ry Geology. 121:121-140.

Welton J.E. 1984. SEM Petrology Atlas. Methods in exploration series. AAPG, Tulsa, Oklahoma, 231p.

Wilson M.D. \& Stanton P.T. 1994. Diagenetic mechanisms of porosity and permeability reduction and enhancement: Reservoir quality assessment and prediction in clastic rocks. SEPM Short Course 30, Tulsa, Oklahoma, SEPM Society for Sedimentary Geology. $\mathrm{p}$ $59-118$.

Zalán P.V., Wolff S., Conceição J.C.J., Astol M.A.M., Vieira I.S., Appi V.T., Zanotto O.A. 1987. Tectônica e sedimentação da Bacia do Paraná. In: Simpósio Sul Brasileiro de Geologia, 3, Curitiba. Atas, $1: 441-477$.

Zalán P.V., Wolff S., Astol M.A.M., Vieira I.S., Conceição J.C.J., Appi V.T., Neto E.V.S., Cerqueira J. R., Marques A. 1990. The Paraná Basin, Brazil. Tulsa: American Association of Petroleum Geologists, Bulletin, Memoir 51:681-708.

Manuscrito A-1549

Revisão aceita em 14 de junho de 2006 